\title{
HABILITATION IN SLOVAKIA AND THE PROBLEM OF ITS NOSTRIFICATION IN POLAND
}

\begin{abstract}
This article concerns significant, current problem of scientific activity, referring at the same time to a series of articles regarding publications and international scientific cooperation published in the last issue of "Annual Center Review".
\end{abstract}

\section{Key words}

Habilitation; nostrification; Poland; Slovakia

\section{Introduction}

The issues of Polish scientists' habilitation implemented in Slovakia has become a legend. Until mid-2016 the Slovak pedagogical-academic title of docent was treated equally to the Polish degree of habilitated doctor (Pol. doctor habilitowany). Due to the change of the agreement between Poland and Slovakia, today recognising Slovak title of docent as an equivalent to habilitated doctor is subjected to nostrification procedure. This solution should favour the protection of Polish science without causing barriers in international scientific cooperation and internationalisation of research. However, new problems arise whose solution requires a change of practice and in particular issues also a change of Polish provisions.

This article concerns significant, current problem of scientific activity, referring at the same time to a series of articles regarding publications and international scientific cooperation published in the last issue of ACR.

\section{Slovak requirements for habilitation}

Habilitation process in Slovakia is determined by explicit legal regulations, very often more clear and precise than in Poland. People who fulfil minimal academic and pedagogical requirements, described in details, may be subjected to this procedure. The candidate should comply with the following criteria:

- 3 years of educational work after obtaining the title of Ph.D.;

- 1 handbook, textbook or educational text of at least $3 \mathrm{AH}^{1}$ volume;

- supervision over 5 finished dissertations;

- with regard to scientific publications: 1 monography or monothematic work of at least $3 \mathrm{AH}$ volume, the authorship of 20 original scientific works with at least 4 articles published in a foreign, reviewed journal and 3 professional articles published in specialised journals and reviewed journals;

- with regard to publication referencing: 12 quotations and 2 quotations in WoS or SCOPUS databases;

- supervision or participation in 2 grant projects.

Postdoctoral dissertation is subjected to 3 reviews by professors and a defence. Application for the award of the pedagogical-academic title of docent is considered by the faculty council and is conferred by rector.

\section{Nostrification of Slovak habilitation in Poland}

Nostrification process of the scientific degree of habilitated doctor, and in the analysed case recognition that the pedagogical-academic title of docent is equivalent to the degree of habilitated doctor, is conducted by the council of the organisational unit authorised to confer such title in the given field of science, in the scientific discipline

$1 \mathrm{AH}=36000$ characters 
which this degree concerns ${ }^{2}$. Discrepancies which sometimes occur between pedagogic specialisation in which the Slovak title of docent is awarded and the Polish field of science and scientific discipline ${ }^{3}$ must be eliminated.

As a rule, the detailed criteria of obtaining habilitation in Slovakia and in Poland are almost identical ${ }^{4}$, but it may be argued that Slovak rules are more strict (quotations, defence of habilitation). The problem is restricted to the general criterion of opening the habilitation procedure, in Poland determined by the Art 16 par. 1 of the Act of 24 March 2003 on scientific degrees and title and degrees and title in the arts [J of Laws of 2017, item 1789]. It states that „a person who holds a doctoral degree and demonstrates scientific and artistic achievements representing a significant contribution to the advancement of a given scientific or artistic discipline, made after the award of the doctoral degree, and who is meaningfully engaged in scientific or artistic activity may be admitted to a habilitation assessment process". The comparison of the Slovak habilitation requirements to the above mentioned criterion allows to state that there is no condition of significant contribution of the author to the advancement of a given scientific (or artistic) discipline. Therefore, habilitation assessment process properly conducted in Slovakia may not refer to this condition at all. Thus, a question arises, what should be the stance of the Polish council conducting nostrification process of the degree of habilitated doctor?

Polish council conducting such process, besides candidates' application form, receives several documents generally determined in the Regulation of the Minister of Science and Higher Education of 8 September 2011. Based on this Regulation, during nostrification process the council may adopt a resolution on the necessity to prepare reviews of the documents confirming scientific achievements which constitute the basis for obtaining the scientific degree. Nostrification process is ended by the council resolution on the recognition of the scientific degree as equivalent to the Polish scientific degree or the degree in arts or on refusal to recognise the scientific degree as

\footnotetext{
See: Regulation of the Minister of Science and Higher Education of 8 August 2011 on nostrification of academic degrees and degrees related to art study obtained abroad (J of Laws No. 179, item. 1067).

3 Compare: Regulation of the Minister of Science and Higher Education of 8 August 2011 concerning areas of knowledge, fields of science and art, and scientific and artistic disciplines (J of Laws No. 179, item 1065).

4 See: Regulation of the Minister of Science and Higher Education of 1 September 2011 on the criteria of assessing the accomplishments of a person applying for the conferment of the degree of habilitated doctor ( $\mathrm{J}$ of Laws No. 196, item 1165).
}

equivalent to the Polish scientific degree or the degree in arts. The council refuses to recognise the scientific degree as equivalent to the appropriate Polish scientific degree or to exempt from nostrifiction procedure in the case when the institution which has conferred the scientific degree was not on the date of issuing the diploma accredited to award scientific degrees within the meaning of domestic law of the country in whose higher education system the institution operates or does not operate in a higher education system of any country.

\section{What the law is and what it should be - remarks}

The last sentence creates a serious interpretative problem. The issue is whether the only reason to refuse to recognise a scientific degree as equivalent to the Polish degree of habilitated doctor constitutes two premises specified in the provisions of the quoted Regulation of the Minister of Science and Higher Education (i.e.: when the institution which has issued the diploma was not on the date of issuing accredited to award scientific degrees within the meaning of domestic law of the country in whose higher education system the institution operates or it does not operate in a higher education system of any country) or there may be other premises depending on the discretion of the council. Grammatical interpretation of this provision inclines to accept the first opinion. However, systemic, purposive and logical interpretation supports the second opinion, which also the Author of this article agrees with. It is logical to read this provision not as a whole premises to refuse to recognise the scientific degree as equivalent to the degree of habilitated doctor but as an obligation to refuse to recognise the scientific degree in the mentioned circumstances. If nostrification process was only to establish the existence of the above mentioned premises, then the whole procedure would be apparent and the sole fact of their existence would not have to be established by the council though separate nostrification procedure but by an appropriate clerk of the Ministry of Science and Higher Education.

On the basis of the binding provisions, an issue arises for the council (and a potential reviewer) whether scientific accomplishments (scientific achievements and postdoctoral dissertation) represent a significant contribution of the author to the advancement of a given scientific (or artistic) discipline. During habilitation procedure in Slovakia this contribution is not considered and the 
issues of minimal achievements, their originality and minimal amount of quotations (required in Slovakia) may not be recognised as equivalent to it. Documents of conferring the pedagogical-academic title of docent do not solve this problem. It requires analysis of additional documents (e.g. review of the Slovak habilitation, review and evaluation of achievements and particular publications) in terms of the significant contribution of the author to the advancement of a given scientific discipline. The problem lies, however, in the fact that the candidate may submit such documents, but formally there is no such obligation. If such documents are not submitted or the premise of significant contribution of the author to the advancement of a given scientific discipline does not arise from them, then the council must conduct independent evaluation on the basis of own beliefs of the council members concerning significant contribution to the advancement of a given scientific discipline. It is worth to emphasise the important difference of the received at the council's request review of the documents confirming scientific achievements and constituting the basis to obtain the scientific degree. The reviewer may evaluate only submitted documents. She does not have the authority to independently evaluate the achievements and postdoctoral dissertation with regard to the significant contribution of the author to the advancement of a given scientific (or artistic) discipline. However, there are no substantive obstacles for every member of the council to establish own, substantive position in this respect, before nostrification voting.

Postulates to consider implementing changes in the currently binding detailed provisions regarding nostrification (i.e. in the Regulation of the Minister of Science and Higher Education of 8 September 2011) should be directed to the Ministry of Science and Higher Education. They arise from the first experiences of recognising as equivalent to the Polish scientific degree of habilitated doctor the pedagogical-academic title of docent in Slovakia. Additional information in this scope are necessary for the council to make rational decision. As a rule, it should be similar as in the Polish habilitation procedure or refer to it. Therefore, a summary of professional accomplishments and information not only about current (or previous) nostrification procedures but also about habilitation processes seem to be essential. In the matter of nostrification of the pedagogical-academic title of docent (and often also in other matters) is necessary an independent, super review of a qualified professor, aiming at establishing the significant contribution of the author's scientific and artistic achievements to the advancement of a given scientific or artistic discipline. The possibility to commission such a review by the council should replace or supplement current review of the documents confirming scientific achievements, constituting the basis to obtain the scientific degree.

\section{Conclusion}

Recognising scientific degrees and titles in international relations serves internationalisation of scientific research and international scientific cooperation. Sometimes however, there are exceptions to this rule which are to protect the level of science in the given country. Basic instrument in this scope is nostrification. In the case of nostrification of the pedagogical-academic title of docent in Slovakia with the scientific title of habilitated doctor in Poland essential is not only the change of international agreement but adjusting the domestic provisions of the country implementing the obligation of nostrification to the new conditions. Without this, the nostrification procedure will be an artificial process causing results difficult to foresee today.

\section{Legal Acts}

Act of 24 March 2003 on scientific degrees and title and degrees and title in the arts (J of Laws of 2017, item 1789).

Regulation of the Minister of Science and Higher Education of 8 August 2011 on nostrification of academic degrees and degrees related to art study obtained abroad ( $\mathrm{J}$ of Laws No. 179, item. 1067).

Regulation of the Minister of Science and Higher Education of 8 August 2011 concerning areas of knowledge, fields of science and art, and scientific and artistic disciplines ( $\mathrm{J}$ of Laws No. 179, item 1065).

Regulation of the Minister of Science and Higher Education of 1 September 2011 on the criteria of assessing the accomplishments of a person applying for the conferment of the degree of habilitated doctor (J of Laws No. 196, item 1165).

\section{Author biography:}

Eugeniusz Ruśkowski - Full Professor, the Head of the Department of Public Finances and Financial Law at Faculty of Law, University of Białystok, Poland. 